\title{
STUDIES IN TEMPERATURE SENSATION. IV. THE STIMULATION OF COLD SENSATION BY RADIATION
}

\author{
By JAMES D. HARDY AND THEODORE W. OPPEL \\ (From the Russell Sage Institute of Pathology in affiliation with the Nere York Hospital and \\ Department of Medicine, Cornell University Medical College, New York City)
}

(Received for publication August 10, 1938)

The first papers of this series $(1,2,3)$ reported methods of using radiant energy as a purely thermal stimulus and demonstrated that the sensory effects of radiation depend upon the temperature changes produced in the skin by the absorption of various spectral bands. The threshold stimulus which activates a warmth sensitive end organ was measured and was differentiated from the sensory threshold of warmth. The sensory threshold was shown to vary when different parts of the body surface were exposed to the stimulus, and this variation depended largely upon the end organ population of the part and upon the ability of the central nervous system to combine or summate discharges resulting from the activation of numerous end organs. On certain parts of the body surface the end organ population appeared to be uniform, and here the relationship between the strength of the threshold stimulus and the size of the stimulated area followed a mathematical formula. This was assumed to be the formula for the summation of end organ responses from that region of the body surface.

The psychological aspects of cold sensation have been studied extensively by Goldscheider (4), Levine and Dallenbach (5), and others, and the physiology by Bazett and McGlone (6) and more recently, by Nafe and Wagoner (7). The importance of temperature sense in the regulation of body heat loss has been recently emphasized by Herrington, Winslow, and Gagge (8), by Jung, Doupe, and Carmichael (9), and by Du Bois (10). The past studies of cold sensation have not been concerned essentially with the relation of cold sense to regulation of body temperature, and it was hoped that with the radiation method more could be learned about how the human body recognizes the temperature of objects in its environment and that any similarities or differences associated with the mechanism of the perception of warmth and cold would be found. As all objects of the temperature of the skin surface or colder radiate in the spectral region longer than $4 \mu$, and inasmuch as the skin has the same optical properties throughout this entire spectral range, we are not concerned with the effects of different wave lengths in the present study. The problem is limited, therefore, to a determination of the threshold stimuli for cold and to a comparison of the summation of responses from cold end organs with the summation of responses from heat end organs.

\section{EXPERIMENTAL}

In the present experiments the technique previously used has been altered to apply to an investigation of cold sensation. The sense of cold was stimulated by exposing a portion of the body surface to a block of solid $\mathrm{CO}_{2}$. The radiant exchange between the skin and the $\mathrm{CO}_{2}$ is conveniently termed "cold" radiation.1 In these experiments the skin, which has become adapted to the general environment, is suddenly exposed to an object much below room temperature so that the heat loss from the skin by radiation is greatly increased. This increase in heat loss is the quantity which is measured as "cold" radiation, and is actually the heat loss of the environment by radiation to the cold object. Thus objects below the general environmental temperature will be sources of cold radiation and those above will be sources of heat radiation.

\section{Measurement of the minimum stimulating amount of cold radiation}

The apparatus used to measure the minimum stimulating amount of cold radiation was essentially the same as that used for determining the minimum stimulating amount of heat radiation and is described in detail in the first paper of this series (1). In place of the incandescent lamp or electric stove used as sources of radiant heat ( $\mathrm{S}$ in Figure 1 of Paper 1) a block of $\mathrm{CO}_{2}$ snow, $20 \times 20 \mathrm{~cm}$., was used as a source of cold radiation. A silver lined truncated cone $(30 \mathrm{~cm}$. long, $22.3 \mathrm{~cm}$. in diameter at its base, and $7.7 \mathrm{~cm}$. in diameter at its truncated

1 As the term "cold" radiation already appears in standard textbooks of physics (See Edwin Edser, Heat for Advanced Students, McMillan and Co., 1929) and is being used by students and engineers interested in air conditioning, acceptance of the term and its definition appear desirable. 
end) served to concentrate the rays in place of the lens which focused the heat rays in some of the former experiments. No filters were used. The strength of the radiation was altered by moving the block of snow towards or away from the subject. A cardboard shutter was held between the $\mathrm{CO}_{2}$ block and the cone, and after the subject had become accustomed to the sensations of the apparatus and the room, the shutter was removed and a stimulating amount of radiation allowed to fall on the subject's forehead for 1 second. This length of time was used for cold stimulation rather than the 3 seconds used for warm stimulation because the cold was perceived much quicker than the warmth. Repeated tests were made until the smallest amount of cold radiation which the subject recognized accurately in this time was found; the strength of the radiation was determined with a small radiometer in the same manner that the warm radiation stimulus was measured.

Circular holes cut in pieces of cardboard limited the size of the skin area irradiated, and threshold stimuli were determined for 8 areas ranging from $3.46 \mathrm{sq} . \mathrm{cm}$. to $1986 \mathrm{sq} . \mathrm{cm}$. The same technique was used to measure reflection of cold radiation that had been used to measure infra-red reflection. Cold reflection was found to be too small (less than 2 per cent) to effect the present results.

\section{Measurements of the thermal changes resulting from cold radiation}

Skin temperature changes resulting from cold radiation were measured by the same technique with which the changes resulting from warm radiation were measured, and that method is described in detail in the second paper of this series (2). The apparatus is shown in Figure 1 of that paper. When the silver lined cone was used to augment the cold radiation, it was mounted on the same axis as the skin temperature measuring radiometer in such a way that it reflected the radiation onto the skin surface while the radiometer was before the constant temperature reference body. Swinging the radiometer into position for measuring skin temperature automatically moved the cone to one side. Curves of the heating of the skin after cold radiation (corresponding to cooling after heat radiation) were formed and from them constant time charts were constructed. They are shown in Figure 1. The details of their formation and their interpretation are the same as for heat radiation and are described elsewhere (2). The lines on this chart show the average cooling of the skin surface by various strengths of cold radiation applied for $15,30,45$, and 60 -second periods. Skin temperature changes reported in this paper are all derived from these charts.

Early in the present investigation it became apparent. that there was a marked difference between the thermal and stimulating effects of the same quantities of radiant heat and cold. Because of the limited available intensity of cold radiation it was necessary to measure even smaller skin temperature changes than had to be meas-

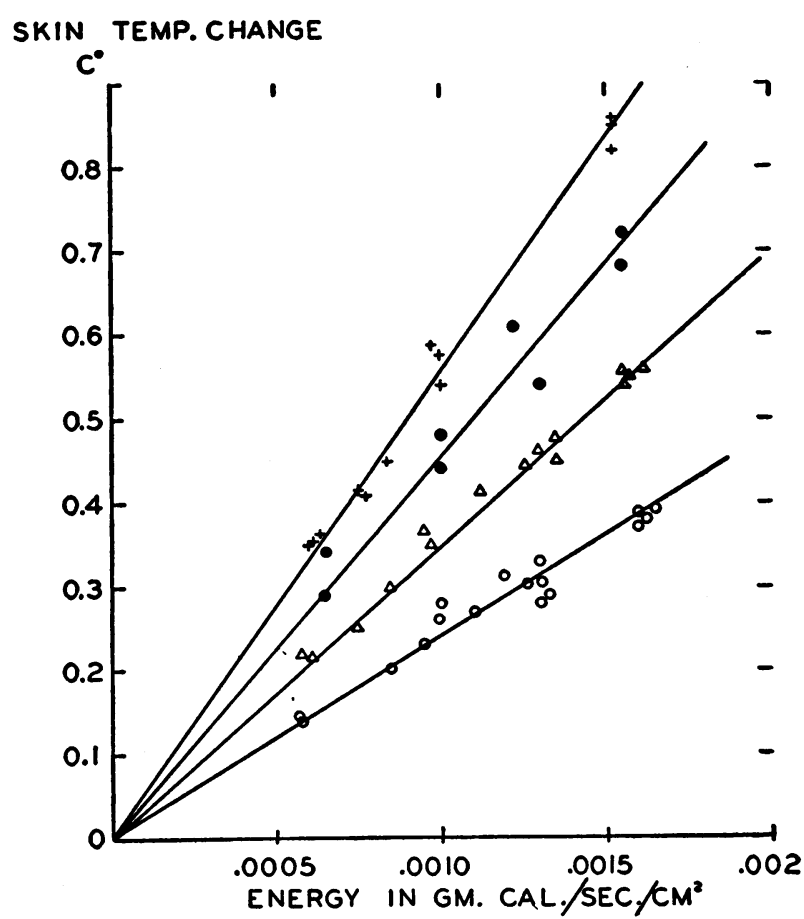

Fig. 1. Constant Time Curves for Cold Radiation

,+ 60 seconds exposure; 9,45 seconds exposure; $\Delta$, 30 seconds exposure; $O, 15$ seconds exposure.

ured in the experiments with warmth. Therefore, a number of tests were made to determine the accuracy of the methods.

\section{Calibration of skin temperature radiometer}

As the method of determining the amount of the change in skin temperature produced by a given exposure to the $\mathrm{CO}_{2}$ involved continuous observation of the skin temperature for some minutes after the exposure, the following experiment was devised to test the procedure. Two Leslie cubes were mounted so that the radiometer could swing readily from one to the other, the thermopile of the radiometer facing directly into the cone of each cube. The water in each cube was stirred constantly by a motor and maintained at constant $\left( \pm 0.01^{\circ} \mathrm{C}\right.$.) temperatures by thermostatically controlled heaters. The temperature of the water was measured by U. S. Bureau of Standards certified thermometers, accurate to $0.001^{\circ} \mathrm{C}$.

One cube served as a constant temperature reference body at $33.70^{\circ} \mathrm{C}$. and the radiometer standardized against it. The radiometer was then swung over to the other cube, which was maintained at $34.55^{\circ} \mathrm{C}$. for 3 minutes, when the heater was turned off and the cube allowed to cool. At intervals of one minute the cube thermometer was read and simultaneously the difference between the temperatures of the two cubes was measured with the radiometer. The results are shown in Figure 2. Ther- 
mometer readings are plotted as solid dots. Radiometer readings as circles. As there was less than $0.005^{\circ} \mathrm{C}$. difference between the temperature readings by these two methods it can be assumed that the radiometer will accurately follow the skin temperature changes for some minutes.

Measurement of temperature changes produced by heat and cold radiation on a blackened metal plate

To make sure that the observed difference in the thermal properties of heat and cold radiation for the skin was not owing to the experimental procedure, the heating and cooling of a thin, blackened, copper plate was observed. One Leslie cube served as a constant temperature reference body and a circular copper plate was mounted $3 \mathrm{~mm}$. in front of the cone of a second Leslie cube, which was also kept at a constant temperature. The front surface of the plate was blackened and a thermocouple was soldered in the middle of it so that its temperature could be continually recorded. After the plate had come to thermal equilibrium, it was irradiated with $0.00105 \mathrm{gm} . / \mathrm{cal} . / \mathrm{cm}^{2} / \mathrm{sec}$. of heat for periods of 30 and 60 seconds, and the subsequent cooling after irradiation was measured by the radiometer. The procedure was repeated, using the same number of calories of cold radiation for the same time periods. The results are shown in Figure 3. Almost identical temperature changes were found after warm and cold irradiation, and there was close agreement between the temperature measured with the radiometer and by the thermocouple.

From the above control experiments we feel that the radiometric measurement of surface temperature by our method is accurate to $\pm 0.005^{\circ} \mathrm{C}$.

\section{RESULTS}

The minimum perceptible cold radiation was measured for several areas on six subjects, all of whom were found to have approximately the same sensory thresholds. On two of these subjects a detailed study of the sensory threshold for cold radiation was made by exposing 8 different sized areas to the radiation stimulus. The 6 smallest areas, ranging from $3.46 \mathrm{~cm}^{2}$ to $40 \mathrm{~cm} .{ }^{2}$, were tested by exposing parts of the forehead. The two larger areas consisted of the whole face and the upper half of the anterior body surface. In Table $I$ the minimum amounts of radiation which could be perceived as cold by each subject on each area are recorded together with the average figures for both subjects. It is evident from this table that, as in the study with radiant heat, the threshold stimulus for cold decreased progressively with each increase in the area of the skin surface tested.

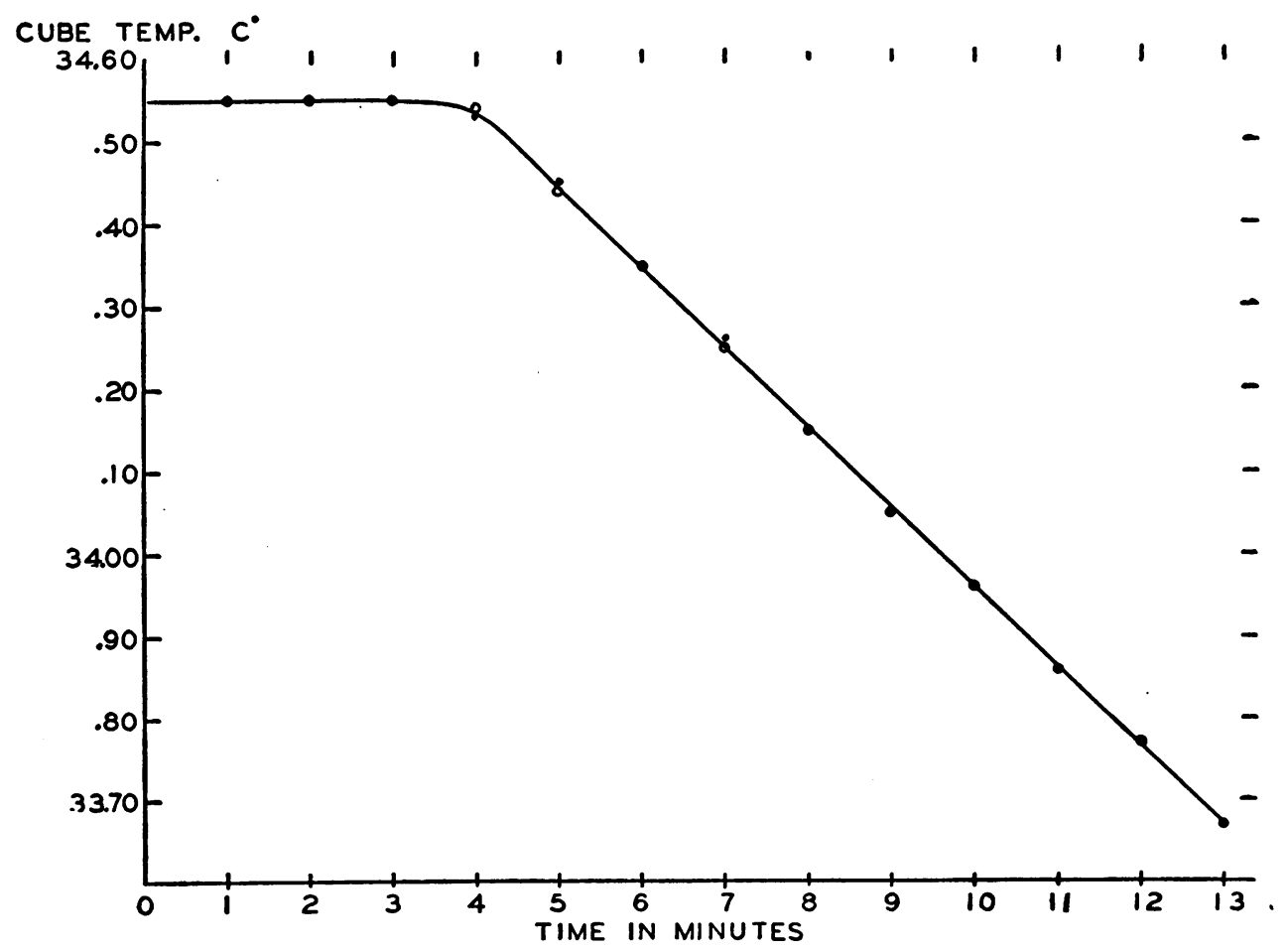

Fig. 2. Calibration Experiment with Skin Temperature Radiometer 


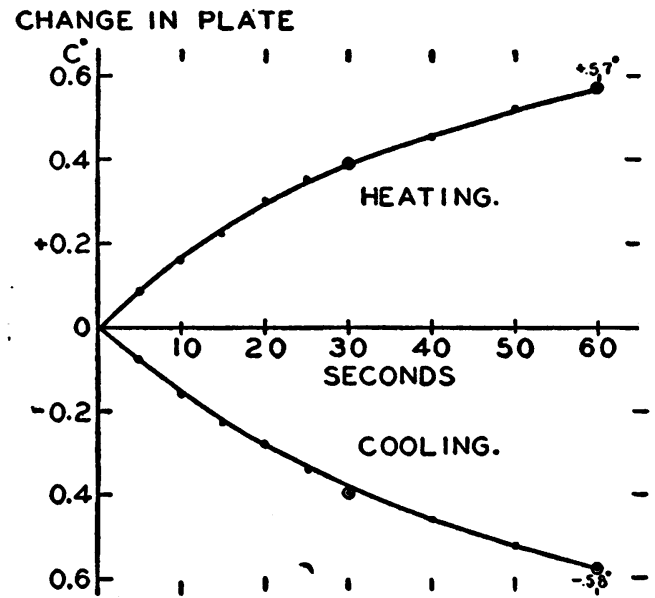

Fig. 3. Temperature Change Produced in a Warm, Blackened, Copper Disc by the Same Intensity of Heat and Cold Radiation

Dots represent measurements with a thermocouple soldered to the disc; circles, radiometer measurements.

It was shown in the previous experiments that a radiation stimulus is a thermal stimulus, effective as a result of the skin temperature change which is produced. In the last column in Table $I$, the changes in the temperature of the surface of the skin produced by the threshold stimuli are shown. They likewise show decreasing values the larger the size of the area tested. The relationship between the threshold stimulus (expressed as surface temperature change) and the size of the area tested is shown graphically in Figure 4. Because of the wide range of values the results are plotted in logarithms. The curve is of the same type as that formed from the results of a similar experiment with non-penetrating infra-red radiation. We were unable to obtain a sufficiently strong cold stimulus to test very small areas. The threshold stimulus for a single end organ found by Bazett and McGlone (6) is shown added to our curve by an interrupted line.

Within the range of radiation intensities used in these experiments the fall of skin temperature was directly proportional to the strength of the radiation applied for a constant time. This is shown on Figure 1, in which skin temperature change is plotted against the strength of the radiation applied for $15,30,45$, and 60 -second periods. The lines drawn between the points are straight and pass through the origin. This result, which was also present in the experiments with heat, indicates that these temperature changes are independent of vasomotor effects and are produced by the absorption of the radiation. There was a striking difference between the thermal effect of heat and cold radiation, cold changing the skin temperature much more than the same number of calories of heat. This is shown on Figure 5, in which the results of experiments with heat and cold are plotted on the same scale. The upper curve indicates changes caused by cold; lower line, changes resulting from heat.

\section{DISCUSSION}

The unequal changes of skin surface temperature produced by identical amounts of heat and

TABLE I

Minimum stimuli for various sized body areas

\begin{tabular}{|c|c|c|c|c|c|}
\hline \multicolumn{2}{|c|}{ Area } & \multirow{2}{*}{$\begin{array}{l}\text { Subject I } \\
\begin{array}{l}\text { gm. cal./ } \\
\text { sec./cm. }{ }^{2}\end{array}\end{array}$} & \multirow{2}{*}{$\begin{array}{l}\text { Subject II } \\
\begin{array}{l}\mathrm{gm} . \mathrm{cal} . / \\
\text { sec./cm.2 }\end{array}\end{array}$} & \multirow{2}{*}{$\begin{array}{l}\text { Average } \\
\begin{array}{l}\text { gm. cal.// } \\
\text { sec./cm. } .^{2}\end{array}\end{array}$} & \multirow{2}{*}{$\begin{array}{c}\begin{array}{c}\text { Skin } \\
\text { temper- } \\
\text { ature } \\
\text { eleva- } \\
\text { tion }\end{array} \\
\text { Rate }\end{array}$} \\
\hline Location & Size & & & & \\
\hline Forehead.... & $\begin{array}{l}\mathrm{cm} .^{2} \\
3.46\end{array}$ & $\begin{array}{l}0.0013 \\
0.0013 \\
0.0013\end{array}$ & $\begin{array}{l}0.0012 \\
0.0014 \\
0.0013\end{array}$ & 0.0013 & $\begin{array}{l}{ }^{\circ} \mathrm{C} . \text { per } \\
\text { second }\end{array}$ \\
\hline Forehead... & 7.08 & $\begin{array}{l}0.00094 \\
0.00097 \\
0.00094 \\
0.00094\end{array}$ & $\begin{array}{l}0.00094 \\
0.00095 \\
0.00092\end{array} \mid$ & 0.00094 & 0.013 \\
\hline Forehead. & 10.0 & $\begin{array}{l}0.00082 \\
0.00079 \\
0.00072 \\
0.00072\end{array}$ & $\begin{array}{l}0.00082 \\
0.00077 \\
0.00072 \\
0.00074\end{array}$ & 0.00076 & 0.011 \\
\hline Forehead.. & 14.5 & $\begin{array}{l}0.00064 \\
0.00072 \\
0.00063\end{array} \mid$ & $\begin{array}{l}0.00059 \\
0.00065 \\
0.00068 \\
0.00062\end{array}$ & 0.00065 & 0.009 \\
\hline Forehead. & 23.8 & \begin{tabular}{|l|}
0.00046 \\
0.00036 \\
0.00051 \\
0.00047
\end{tabular} \mid & $\begin{array}{l}0.00051 \\
0.00051 \\
0.00048 \\
0.00050\end{array}$ & 0.00048 & 0.007 \\
\hline Forehead... & 40.0 & $\begin{array}{l}0.00046 \\
0.00043\end{array}$ & $\begin{array}{l}0.00041 \\
0.00038\end{array}$ & 0.00042 & $0.006-$ \\
\hline Entire face. & 197 & \begin{tabular}{l|}
0.00033 \\
0.00032
\end{tabular} & $\begin{array}{l}0.00036 \\
0.00033\end{array}$ & 0.00033 & 0.004 \\
\hline $\begin{array}{l}\text { Face and } \\
\text { chest.. }\end{array}$ & $\begin{array}{l}1,680 \text { (I) } \\
1,940 \text { (II) }\end{array}$ & $\begin{array}{l}0.00032 \\
0.00027\end{array}$ & $\begin{array}{l}0.00026 \\
0.00022\end{array}$ & 0.00027 & $0.004-$ \\
\hline
\end{tabular}




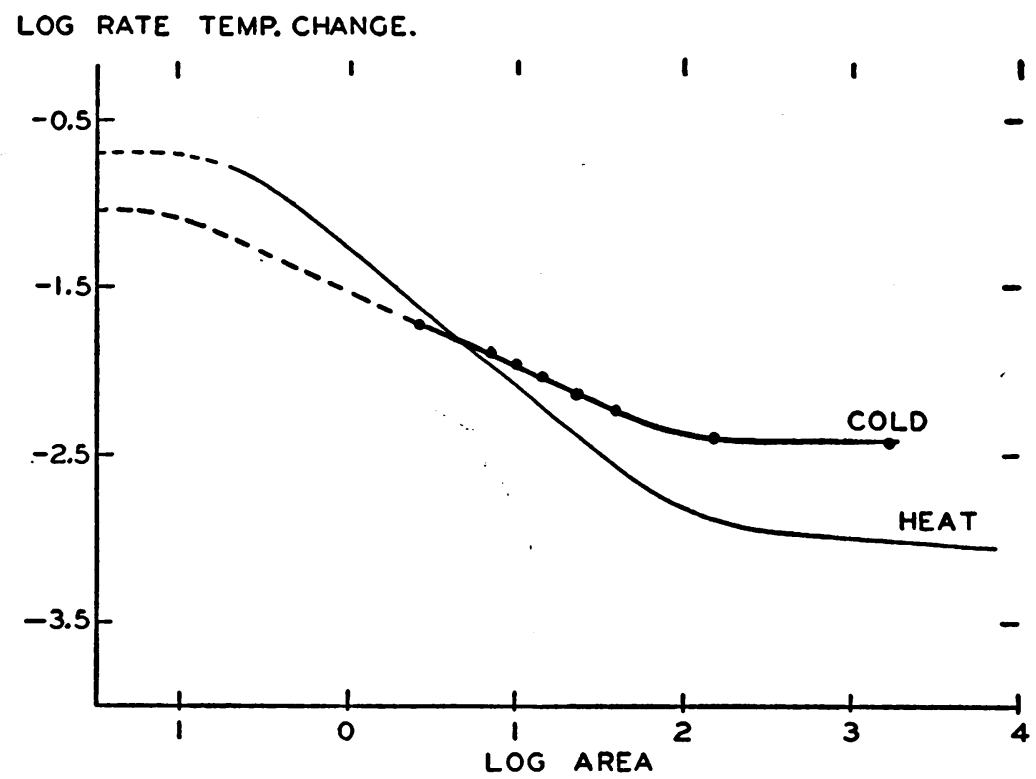

Fig. 4. Comparison of Heat and Cold Sensation as Functions of Temperature Change and Exposed Area

cold radiation was an unexpected and at first perplexing finding. The experiments in which the temperature of the blackened copper plate was measured after warm and cold radiation indicated clearly that the measurements were accurate and that the observed phenomena were not owing to an error in technique. Vasomotor changes seemed to be eliminated as a cause by the linear relationship found between surface temperature change and the quantity of the heat or cold radiation absorbed. Bazett and McGlone (6) had reported that cold is conducted into the skin more slowly than heat and it seemed that this might explain our results on a purely physical basis. At the room temperature in which we worked the skin surface was colder than the deeper structures and heat was constantly flowing out. A simple experiment with artificial material was devised to stimulate the conditions in the skin.

A piece of beef muscle $7 \mathrm{~mm}$. thick was pasted on one side of a Leslie cube. The water in the cube was maintained at $37.20^{\circ} \mathrm{C}$. It was then irradiated for periods of 30 and 60 seconds with equal amounts of heat and cold, and the change in its surface temperature after each period was measured with the radiometer in the same way that the temperature of the skin surface was measured after irradiation. The results are shown on Figure 5 together with the changes in skin surface temperature produced by the same amounts of radiation. The lower curve is the temperature change caused by heat radiation, the upper curve by cold radiation. Almost exactly the same temperature changes occurred on the meat and on the skin surface. The difference observed between the thermal effect of warm and cold radiation therefore seems to depend upon the thermal properties of tissue and is entirely independent of the blood flow in the skin. This

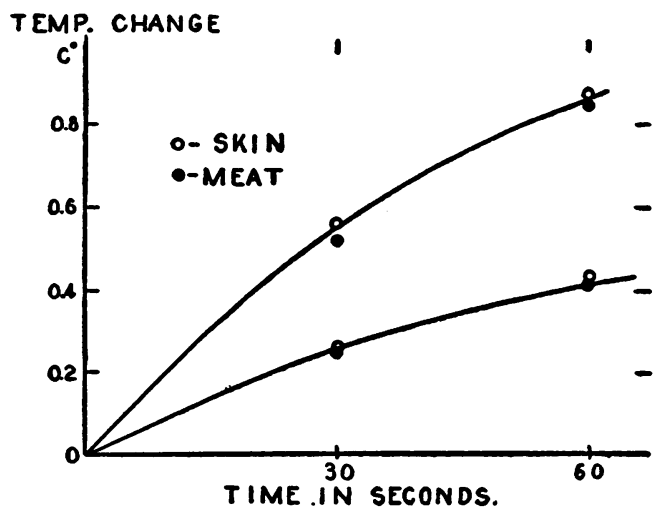

Fig. 5. Temperature Changes Produced by Equal Amounts of Heat and Cold Radiation. Upper Curve, Cold Radiation; Lower Curve, Heat Radiation 
phenomenon occurs only during short periods of irradiation, for the circulation in the skin is altered after one or two minutes' exposure and for long periods like amounts of heat and cold radiation do not cause equal and opposite skin temperature changes.

Because of the phenomenon just discussed, it is obvious that heat and cold sensation cannot be compared on the basis of radiation intensities and that comparison is possible only when the change of the skin temperature is considered as the stimulus. In our results the actual temperature changes at the end organs are not known, for they will depend on thermal conduction into the skin. We have contrasted the skin surface temperature increase or decrease associated with minimal sensations of warmth and cold for a number of different sized areas. This is graphically shown on
Figure 4. Analysis of these curves reveals certain interesting differences between the perception of warmth and cold. In the region of large areas the curves are horizontal and further increase in the size of the area tested, although increasing the number of end organs stimulated, fails to reduce the threshold stimulus. The minimum temperature change has been reached to which end organs will respond. This threshold for cold end organs is a fall of skin temperature of $0.004^{\circ} \mathrm{C}$. per second and is much greater than the threshold for warm end organs of $0.001^{\circ} \mathrm{C}$. per second.

The curve for cold sensation slopes more gradually and eventually crosses the curve for heat sensation so that in the region for small areas the sensory threshold for warmth is higher than the sensory threshold for cold. This, together with Bazett and McGlone's value for the threshold for

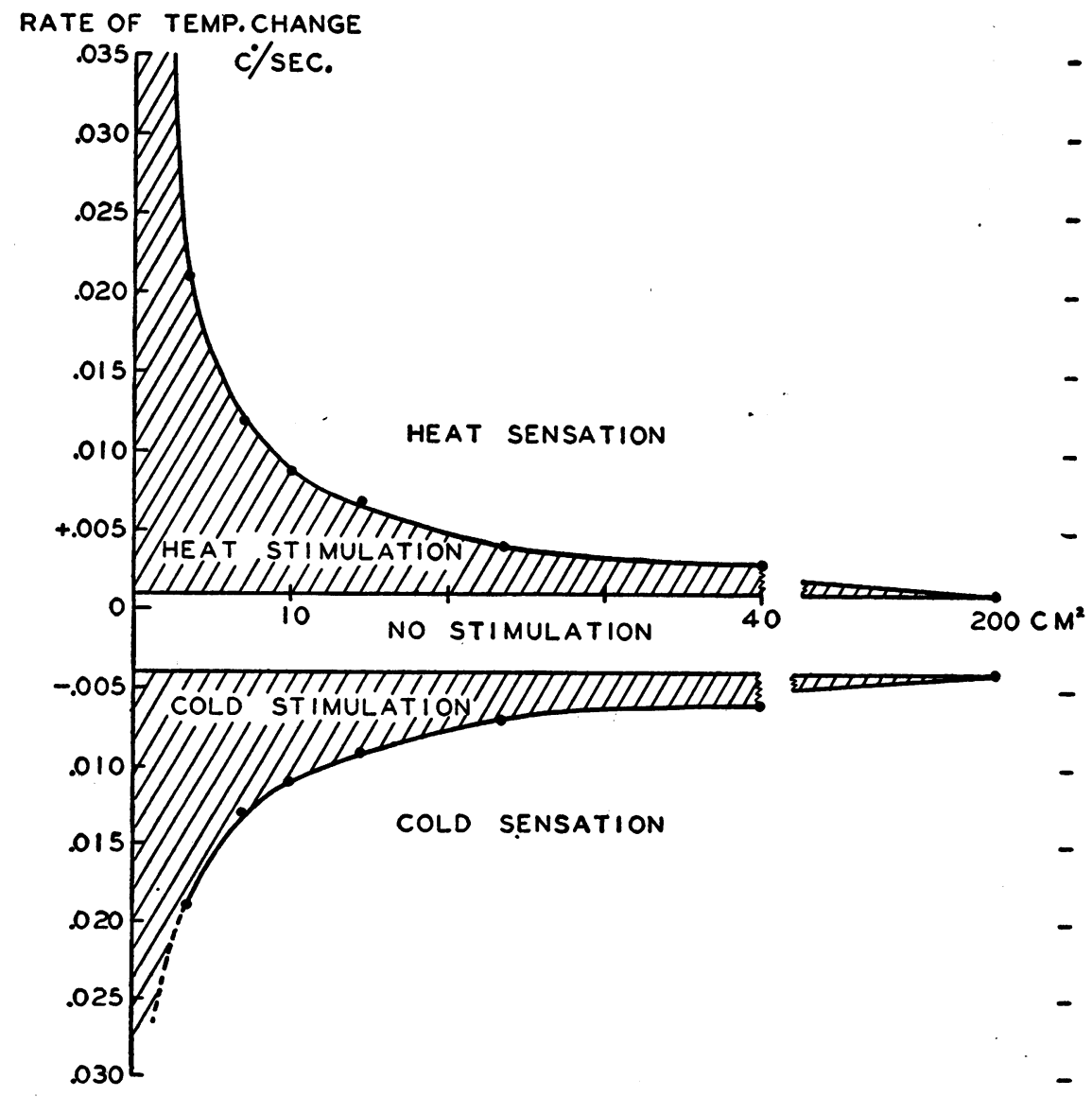

Fig. 6. Temperature Sensation as a Function of the Rate of Skin Temperature Change and Area Exposed

(See text for detailed description.) 
a single end organ, indicates that the number of cold endings is greater than that of the heat endings and that responses from warm end organs are summated more effectively than responses from cold end organs.

These findings strongly support the belief that separate end organs respond to increases and to decreases of skin temperature. An elevation of skin surface temperature of $0.001^{\circ} \mathrm{C}$. per second activates heat receptors; a fall of $0.004^{\circ} \mathrm{C}$. per second, cold receptors. These responses take place within a range of skin temperatures of several degrees, the exact limits of which were not determined. It is entirely possible for an object remaining at constant temperature to stimulate warm receptors when the skin is cold and cold receptors when the skin is warm. The warmness or coldness of any object is therefore a physiological property dependent entirely upon its effect in' altering skin temperature. This effect can be brought about by vasomotor change, by vaporization, draughts or the conduction or radiation of heat or cold to the skin. There is no evidence from these experiments to support the contention of Nafe and Wagoner (7) that temperature sensation is secondary to vasomotor responses to thermal stimuli.

To summarize these experiments on the perception of heat and cold by the human organism in a comfortable environment, we have added Figure 6. The upper half of the chart represents the change in sensory threshold for heat over a wide range of areas on the face and anterior thorax; the lower half, the change for cold over the same areas. The regions external to the curves represent conditions under which sensation of warmth or cold is experienced; the ruled regions, conditions under which end organs are responding but no sensation is evoked. The clear portion between the ruled areas show the degree that the skin temperature can be raised or lowered without activating thermal receptors.

\section{SUMMARY}

Using the radiation technique previously described, the end organs in the skin which are sensitive to cold were stimulated. The term " cold " radiation was defined. The source of cold radiation was a block of $\mathrm{CO}_{2}$ snow, the rays from which were concentrated onto the skin by a large silver cone. The foreheads of six subjects were tested and the individual sensitivity to cold radiation found to be approximately the same. Two subjects were studied in detail by determining the minimum stimulating intensities of cold radiation for areas of different sizes. The thermal changes produced at the skin surface by these radiations were measured to $\pm 0.005^{\circ} \mathrm{C}$. with a radiometer.

\section{CONCLUSIONS}

1. The number of cold end organs per unit area is greater than the number of heat endings and they are nearer to the skin surface.

2. On the forehead, spatial summation of cold sensation follows the same pattern as for heat sense but the summation is poorer.

3. The threshold of thermal stimulation for a cold end organ is a fall in skin temperature of $0.004^{\circ} \mathrm{C}$. per second.

4. Cold radiation produces about twice the rate of change in skin temperature, calorie for calorie, as does heat radiation.

5. Temperature sensation does not depend upon vascular changes in the skin.

\section{BIBLIOGRAPHY}

1. Oppel, T. W. and Hardy, J. D., Studies in temperature sensation. I. A comparison of the sensation produced by infra-red and visible radiation. J. Clin. Invest., 1937, 16, 517.

2. Oppel, T. W. and Hardy, J. D., Studies in temperature sensation. II. The temperature changes responsible for the stimulation of the heat end organs. J. Clin. Invest., 1937, 16, 525.

3. Hardy, J. D. and Oppel, T. W., Studies in temperature. III. The sensitivity of the body to heat and the spatial summation of the end organ responses. J. Clin. Invest., 1937, 16, 533.

4. Goldscheider, A., Thermoreceptoren. Vol. 9, Pt. 1, Handbuch der normalen und Pathologischen Physiologie. Berlin, Springer, 1926.

5. Levine, H. A. and Dallenbach, K. M., Adaptation of cold spots under continuous and intermediate stimulation. Am. J. Psychol., 1936, 48, 485.

6. Bazett, H. C. and McGlone, B., Studies in sensation. II. The mode of stimulation of cutaneous sensations of cold and warmth. Arch. Neurol. and Psychiat., 1932, 27, 1031.

7. Nafe, J. P. and Wagoner, K. S., V. The effect of thermal stimulation upon dilation and constriction 
of the blood vessels of the skin of a contralateral hand. J. Psychol., 1936, 2, 461.

8. Herrington, L. P., Winslow, C. E. A., and Gagge, A. P., The relative influence of radiation and convection upon vasomotor temperature regulation. Am. J. Physiol., 1937, 120, 133.
9. Jung, R., Doupe, J., and Carmichael, E. A., Shivering: A clinical study of the influence of sensation. Brain, 1937, 60, 28.

10. DuBois, E. F., The mechanism of heat loss and temperature regulation. The Lane Medical Lectures, Stanford University Press, 1937. 